to antagonism and stalemate. In the treatment of Singaporean patients, we determine whether they sought traditional healers (often they would volunteer this information). While we do not forbid them from continuing to do so, nor disagree with their beliefs, we do explain to them the concept of the Western model of mental illness, so as to improve compliance with psychiatric medication.

DAvid, A. S. (1990) Insight and psychosis. British Journal of Psychiatry, 156, 798-808.

SALLEH, M. R. (1989) The consultation of traditional healers by Malay patients. Medical Journal of Malaysia, 44, 3-13.

WING, J. K., COOPER, J. E. \& SARTORIUS, N. (1974) Measurement and Classification of Psychiatric Symptoms. Cambridge: Cambridge University Press.

Department of Psychological Medicine

National University Hospital

Lower Kent Ridge Road

Singapore 0511

\section{Clozapine and NMS}

SIR: Some patients given neuroleptics after recovering from neuroleptic malignant syndrome (NMS) have not experienced a recurrence of the syndrome (Meltzer, 1973; Rosebush et al, 1989; Pope et al, 1991), although others have (Buckley et al, 1991). The risk of recurrence of NMS may be reduced by allowing two weeks between the episode of NMS and the reintroduction of neuroleptics, by the gradual titration of neuroleptic dosage, and by termination with early signs of a recurrence. The choice of neuroleptic drug is less clear, and rechallenge with the same typical neuroleptic drug, or an agent of a different chemical structure, appears unrelated to the risk of recurrence of NMS (Buckley et al, 1991).

While the recent report by Weller \& Kornhuber (Journal, December 1992, 161, 855-856) concerning the absence of an NMS recurrence in eight of their nine patients treated with clozapine as a rechallenge agent is encouraging, it is nevertheless premature to suggest that NMS, by itself, provides sufficient clinical indication for clozapine therapy. This is not significantly better than the results in other series (Rosebush et al, 1989; Pope et al, 1991). The other significant side-effects associated with clozapine therapy for treatment-refractory schizophrenia especially agranulocytosis (Meltzer, 1992), the ability of clozapine itself to induce NMS, and the potential for diagnostic confusion between fever, hypo- or hypertension, tachycardia, and comparable effects in NMS - suggest that an episode of NMS is not a sufficient reason to justify a trial of clozapine. Treatment-resistance and intolerance of any neuroleptic drug (e.g. severe tardive dyskinesia or dystonia) are the key indications in schizophrenia for clozapine therapy.

Buckley, P., Freyne, A., McCarthy, A., et al (1991) Neuroleptic malignant syndrome - a follow-up study. Irish Journal of Medical Science, 160, 45-47.

MeLtZER, H. Y. (1973) Rigidity, hyperpyrexia and coma following fluphenazine enthanate. Psychopharmacologia, 29, 337-346.

- (1992) Dimensions of outcome with clozapine. British Journal of Psychiatry, 160 (suppl. 17), 22-29.

Pope, H. G. JR, Aizley, H. G., KeCK, P. E. JR, et al (1991) Neuroleptic malignant syndrome: long-term follow-up of 20 cases. Journal of Clinical Psychiatry, 52, 208-212.

Rosebush, P. I., STEwart, T. D. \& GelenberG, A. J. (1989) Twenty neuroleptic rechallenges after neuroleptic malignant syndrome in 15 patients. Journal of Clinical Psychiatry, 50, 295-298.

\section{Peter F. BuCKLeY} Herbert Y. MELTZER

Department of Psychiatry

Case Western Reserve University

2040 Abington Road

Cleveland, Ohio 44106, USA

\section{In defence of clozapine}

SIR: I feel that Dr Healy's excellent and thoughtprovoking 'Devil's advocate' piece about clozapine should not pass without a few further comments to add to Drs McKenna \& Bailey's cogent defence (Journal, January 1993, 162, 23-29 and 32-37 respectively). In condemning clozapine, Dr Healy uses some misplaced logic and reinterpretation of published findings.

Firstly, the comparisons with other treatments are not really relevant. Coronary artery bypass surgery is no longer a dilemma. It was introduced before the advent of calcium-channel blockers and orally absorbable long-acting nitrates and indeed, for a while, was an expensive but realistic option for treatment. With the advent of pharmacological alternatives, no cardiologist would advocate such expensive treatment in advance of cheaper drug treatment, unless there was an immediate lifethreatening indication (e.g. main stem disease). Similarly, the analogy with newer oncological drugs is misplaced. The circumstances surrounding their use means, unlike clozapine, they are essentially untested treatments often tried as a last resort. At best, they may go through open familiarisation trials in very sick patients. It is usually late on in the drugs' lifespan that they would go through rigorous testing.

Perhaps more meaningful comparisons would be with a 'budget-busting' drug such as cyclosporin, 
which has many similarities. It was hailed as a dramatic breakthrough in immunosuppression, is expensive, was greeted with scepticism, and has life-threatening side-effects (interstitial fibrosis) which require close supervision. Despite this it has gained universal acceptance and has made transplantation more widely available and has improved survival. No one begrudges its cost. Another possible useful comparison could be made with warfarin. This gained universal acceptance by virtue of the fact that it is obviously good. There is not a single clinical trial anywhere on warfarin in the literature. The point here is that $\mathrm{Dr}$ Healy chooses to ignore the very valuable anecdotal, but now extensive, clinical experience that clozapine is an improvement on previous treatments. Both academics (Cutting \& Reveley, 1991) and clinicians (Launer, 1991) attest to the drug's superiority.

Turning to the Kane et al trial, (1988); Dr Healy's post-hoc criticism of this excellent piece of work is uncharitable. Firstly, it is not fair to say the patients had $1800 \mathrm{mg}$ of chlorpromazine. This was a flexibledose-ranging regime, $1800 \mathrm{mg} /$ day being the most any one patient received. Furthermore, doses greater than $1000 \mathrm{mg}$ were only allowable in the second half of the trial, to guard against possible over-treatment. Secondly, the patients were recruited from elsewhere having already fulfilled established criteria for resistance, and then underwent a further trial of resistance with haloperidol. It is not credible to suggest that the patients were systematically worsened by overtreatment at each and every stage of this filter. Thirdly, to pick over the details of whether Dr Kanes' patients were truly resistant or not misses the general point of the exercise. Clozapine is effective across the board in schizophrenia, and the point of its use is really whether there is a subset of particularly disabled patients, for whatever reason (treatmentrefractory or neuroleptic-sensitive), in whom the drug may justify the risk of agranulocytosis (with monitoring, of course). The dismissive comparison with insulin-coma treatment is illogical. This is the 'It'll never fly' argument. To condemn something on the basis of past failure smacks of intellectual nihilism, implicitly suggesting all research endeavours are a waste of time.

In my opinion, Dr Healy is one of the UK's leading psychopharmacologists and he has valuably adopted a reasonable posture as a buffer to the evangelising about clozapine. My own stance would be that the early clinical-trial data is unequivocal, the Kane et al trial is indisputable, and the clinical impression of clozapine from its now numerous users are unambiguously impressive.
There have been a number of these exercises cautioning the use of clozapine (see also Lancet (1992)) and it invokes a hazy recollection of a Guinness commercial in the 1960 s... something about not liking it, but never having tried it!

Cutting, J. \& Reveley, A. M. (1991) Expert opinion: clozapine. Psychiatric Bulletin, 15, 617.

KANE, J., Honigfeld, G., Singer, J., et al (1988) Clozapine for the treatment resistant schizophrenic. Archives of General Psychiatry, 45, 789-796.

LANCET (1992) Editorial. Lancet, 339, 276-277.

LAUNER, M. (1991) Experience with clozapine. Psychiatric Bulletin, 15, 223-224.

Institute of Psychiatry

ROBERT KERWIN

De Crespigny Park

Denmark Hill

London SE5 8AF

\section{Clozapine, cognition, and schizophrenia}

SIR: Goldberg et al (Journal, January 1993, 162, 43-48) argue that the cognitive deficits of schizophrenia are independent of the psychosis and as such do not respond to clozapine. They go on to postulate that the cognitions may actually deteriorate on clozapine and this may be due to the drug's anticholinergic properties. They subjected the patients to ten neuropsychological tests, some on two occasions, and used the Brief Psychiatric Rating Scale (BPRS) and the Clinical Global Impression scale (CGI) to rate their clinical change.

On the surface this seems totally exhaustive and an important development until we look at the 15 patients more closely. Six patients were on lithium before the clozapine phase and six were on lithium in the clozapine phase: four of these were the same patients continued on lithium so, in all, eight patients had received lithium either before or after clozapine. Of the seven patients who had never received lithium, one patient had received lorazepam and two had received anticonvulsants.

Lithium carbonate is described in the data sheet as being associated with memory impairment during long-term use and there is a theoretical risk of neuroleptic malignant syndrome possibly due to antidopamingeric actions when it is used with clozapine, and so the lack of change in the cognitions is not so simple to explain. In addition, many clinicians feel that benzodiazepines in long-term use may damage cognitive functions and the use of anticonvulsants, if given for epileptiform conditions (we are not told about this in the paper), may indicate long-standing brain damage. 